\title{
A INFLUÊNCIA DAS CLASSES DE DECLIVIDADES NA CONSTRUÇÃO DO MAPA DE SUSCETIBILIDADE Ȧ EROSÃO LAMINAR
}

\section{the influence of classes of steepness in the construction of map of susceptibility to laminate erosion}

\author{
Flávio Alves Sousa ${ }^{1}$
}

aaCaa

\begin{abstract}
Resumo
No estudo da suscetibilidade erosiva dos solos o fator declividade é fundamental, portanto havia uma dúvida sobre quais intervalos de declividades utilizar para construção do mapa de declividades e se a variação nos intervalos de declividades influenciaria de maneira significativa o resultado final, ou seja, a configuração do mapa de suscetibilidade erosiva. Como teste, utilizou-se dois mapas de declividades, com intervalos de declividades diferentes para avaliar o resultado final sobre o mapa de suscetibilidade erosiva. Neste caso foi mapeada a bacia hidrográfica do ribeirão Santo Antônio, no município de Iporá, situado na região oeste do Estado de Goiás. A referida bacia tem uma área de $630 \mathrm{~km} 2$. A partir dos mapas de declividades, foram confeccionados dois mapas de suscetibilidade erosiva, a fim de comparar o resultado final. O resultado não apresentou diferença significativa dos mapas, o que levou a pensar que apenas a alteração no número de classes de solos ou a alteração da metodologia poderia provocar alterações na configuração final dos mapas.
\end{abstract}

Palavras-chave: Declividades, Erosão, Bacia hidrográfica.

\begin{abstract}
In the study of the erosive susceptibility of soils the factor steepness is fundamental, therefore there was a doubt on which intervals of steepness to use for construction of the map of steepness and if the variation in the intervals of steepness would influence in a significant way the final result, in other words, the configuration of the map of erosive susceptibility. As test, were used two maps of steepness, with intervals of different steepness to evaluate the final result on the map of erosive susceptibility. In this case the hydrographic basin of the brook Santo Antônio was mapped, in the municipal district of Iporá, located in the area west of the State of Goiás. The referred basin has an area of $630 \mathrm{~km} 2$. Starting from the maps of steepness, two maps of erosive susceptibility were made, in order to compare the final result. The result didn't present significant difference of the maps, what took to think that just the alteration in the number of classes of soils or the alteration of the methodology could provoke alterations in the final configuration of the maps.
\end{abstract}

Key words: Declivity, Run off, Hydrographic Basin

\begin{abstract}
Resumen
En el estudio de la susceptibilidad erosiva de las tierras el factor pendiente es fundamental, todavia había una duda por consiguiente en que los intervalos de pendiente para usar para la construcción del mapa de pendiente y si la variación en los intervalos de pendiente influenciaria de una manera significante el resultado final, en otros términos, la configuración del mapa de susceptibilidad erosiva. Como la prueba, se usó dos mapas de pendiente, con los intervalos de pendiente diferente para evaluar el resultado final en el mapa de susceptibilidad erosiva. En este caso la cubeta del ribeirão Santo Antônio fue trazado, en el distrito municipal de Iporá, localizado en el oeste del área del Estado de Goiás. La cubeta referida tiene una área de $630 \mathrm{~km} 2$. Empezando de los mapas de pendiente, dos mapas de susceptibilidad erosiva eran hecho para comparar el resultado final. El resultado no presentó diferencia significante de los mapas, lo que tomó para pensar que simplemente la alteración en el número de clases de tierras o la alteración de la metodología pudiera provocar las alteraciones en la último configuración de los mapas.
\end{abstract}

Palabras-Claves: Declive, Escapado, Cubeta hidrografica.

(1) Prof. Dr. da Universidade Estadual de Goiás - Av R2 Qd.01, Jardim Novo Horizonte II, CEP: 76200-000, Ipora (GO), Brasil. Tel: (+55 64) 6031489 - flaueg@hotmail.com

$$
\text { aaaa }
$$




\section{INTRODUÇÃO}

A área considerada neste artigo foi a da bacia hidrográfica do ribeirão Santo Antônio no município de Iporá, estado de Goiás, distante da capital (Goiânia), 216 km.

A análise aqui realizada faz parte de um estudo mais complexo sobre o uso e manejo na bacia hidrográfica em questão, onde se utilizou de um mapeamento geoambiental prévio para conhecer a realidade física da área com a finalidade de auxiliar num planejamento sustentável para o uso da bacia.

Os dados cartográficos foram retirados de um mapa-base construído a partir das cartas topográficas Folhas SE-22-V-B-III (Iporá) e SE-22-V-B-IV (Amorinópolis), ambas editadas pelo Instituto Brasileiro de Geografia e Estatística (IBGE), com edição em 1976 e escala 1:100.000.

De maneira geral a área apresenta uma configuração topográfica bastante complexa, o que requer atenção na sua utilização. Na geologia aparecem rochas de idade paleozóica como os granitos do complexo granítico gnáissico Iporá/Caiapó, rochas sedimentares das Formações Furnas e Ponta Grossa de idade Devoniana, Gabros e Piroxenitos de filiação alcalina da provincial alcalina de Goiás (PAGO), e idade Cenozóica.

O clima predominante é o Aw de Koppen, com um período seco (abril a setembro), e outro chuvoso (outubro a março), com um índice médio de precipitação entre 1500 e $1700 \mathrm{~mm}$, (SOUSA, 2006). A geomorfologia apresenta três unidades regionais definidas por Mamede et al (1983) e representadas na Folha SE-22 (Goiânia), sendo elas: Planalto Central Goiano - Planalto do Alto Tocantins-Paranaíba, Planaltos e Chapadas da Bacia Sedimentar do Paraná - Planalto Setentrional da Bacia do Paraná e Depressão do Araguaia. Apresenta ainda uma ampla variação de classes de solos como os Latossolos, Argissolos, Cambissolos e Neossolos Litólicos.

A vegetação nativa faz parte do domínio fitogeográfico do Cerrado, onde ocorrem principalmente as fitofisionomias de cerrado strictu sensu, Floresta Estacional Semidecidual e Mata de Galeria. De maneira geral a bacia apresenta uso e ocupação predominantemente de pastagem, que ocupa em torno de $75 \%$ da área.

A realização deste artigo resultou da dúvida sobre os resultados que se obteriam em relação à construção de um mapa de suscetibilidade à erosão laminar da área, já que se pretendia ao final do estudo fazer uma análise da aptidão das terras, baseada na metodologia de Ramalho Filho \& Beek (1995), e estes autores propunham intervalos de declividades em seu trabalho diferentes da proposta de Salomão (1996), sendo que a metodologia utilizada para a construção do mapa de suscetibilidade erosiva foi extraída deste ultimo autor.

Seguindo neste raciocínio, resolveu-se realizar um experimento para verificar se haveria grande discrepância no resultado do mapa de suscetibilidade erosiva, considerando os intervalos de declividade propostos pelos diferentes autores. Para isso foram gerados dois mapas de declividade e dois mapas de suscetibilidade à erosão laminar, conforme descrito no item a seguir.

\section{ASPECTOS DE METODOLOGIAE TÉCNICA}

Os mapas de declividade foram construídos tendo como base as curvas de nível e pontos cotados extraídos das cartas topográficas Folha SE.22.V.B.III (Iporá) e SE.22.V.B.IV (Amorinópolis) em escala 1:100.000 e eqüidistância de 50 metros. As informações de altitude (curvas de nível/ pontos cotados) foram exportadas no formado DXF para um banco de dados previamente criado em ambiente do Sistema de Informação Geográfica (SIG) do software SPRING desenvolvido pelo Instituto Nacional de Pesquisas Espaciais (INPE). Com os dados de altitude foi então gerada uma grade TIN onde se adotou os seguintes fatiamentos de declividades:

Mapa 1 - de 0 a 3\% onde o relevo é plano a praticamente plano; 3 a $8 \%$ relevo suave ondulado; 8 a 13\% moderadamente ondulado; 13 a 20\% ondulado; 20 a $45 \%$ forte ondulado; 45 a 
100\%, montanhoso; acima de 100\%, relevo escarpado, conforme proposta de Ramalho Filho \& Beek (1995).

Mapa 2 - desenvolvido com a mesma técnica, porém utilizando as classes de declividades propostas por Salomão (1996), quais sejam 0 a 6\%, 6 a 12\%, 12 a $20 \%$ e maior que $20 \%$.

\section{Mapa de Suscetibilidade à erosão laminar}

A obtenção de informações sobre suscetibilidade erosiva foi conseguida inicialmente pela confecção do mapa de declividades. A metodologia utilizada foi a de Salomão (1996). A partir daí foram elaborados dois mapas preliminares de suscetibilidade à erosão laminar, sendo um com o cruzamento das classes de declividades propostas por Ramalho Filho \& Beek (1995), e outro com as declividades propostas por Salomão (1996).

A suscetibilidade à erosão laminar na área de estudo foi obtida de maneira parcial, conforme a metodologia de Salomão (op. cit), que propõe o cruzamento de informações de erodibilidade com a declividade, que resulta em um mapa preliminar de suscetibilidade à erosão laminar. Na continuação do processo cruza-se o mapa de erosividade e de comprimento das encostas para se chegar ao mapa final de suscetibilidade à erosão laminar, sendo que no caso deste estudo, chegou-se apenas até ao mapa preliminar de suscetibilidade á erosão laminar, que é o resultado do cruzamento das classes de erodibilidade dos solos com seus respectivos potenciais erosivos, com o mapa de declividades, conforme Figura 1.

Os índices de erodibilidade dos solos foram extraídas de Bertoni e Lombardi Neto (1985) que realizaram experimentos de erodibilidade dos solos para o Estado de São Paulo, onde estabeleceram as classes de erodibilidade com base nos índices relativos de fragilidade conforme o tipo de solo. Embora estes índices não sejam os mais adequados para a área estudada por questões climáticas diferenciadas, foram utilizados por não haver até o momento do estudo, trabalhos específicos sobre a erodibilidade dos solos da região. O Quadro 1 mostra as classes de solos e as suas respectivas erodibilidades.

Para determinação da erodibilidade dos solos, foi elaborado o mapa de solos da bacia em escala 1:100.000. A elaboração foi conseguida através de análise visual de imagem de satélite, por avaliação do modelo numérico do terreno (MNT) e trabalho sistemático de campo.

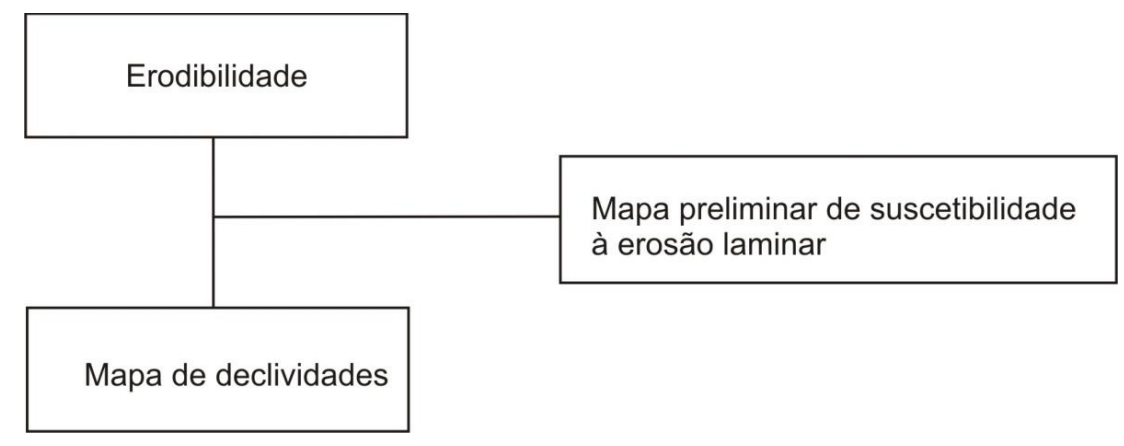

Figura 1 - Roteiro de elaboração do mapa preliminar à erosão laminar. Adaptado de Salomão (1996).

Conhecidos os índices relativos de cada unidade pedológica classifica-se as classes de erodibilidade em número de cinco (5), representadas em algarismos romanos, sendo que quanto menor o valor da classe, maior o índice de erodibilidade. 
Quadro 1 - Classes de erodibilidade.

\begin{tabular}{|c|c|c|}
\hline Classes de erodibilidade & $\begin{array}{c}\begin{array}{c}\text { Índices relativos de } \\
\text { erodibilidade }\end{array} \\
\end{array}$ & Unidades Pedológicas \\
\hline I & 10 a 8,1 & $\begin{array}{c}\text { - Cambissolos, } \\
\text { - Solos Litólicos, } \\
\text { - Podzólicos abruptos, textura arenosa média } \\
\text { - Areias Quartzosas }\end{array}$ \\
\hline II & 8,0 a 6,1 & $\begin{array}{l}\text { - Podzólicos não abruptos, textura média/argilosa, e textura } \\
\text { média }\end{array}$ \\
\hline III & 6,0 a 4,1 & - Podzólicos de textura argilosa \\
\hline IV & 4,0 a 2,1 & $\begin{array}{l}\text { - Latossolos de textura média } \\
\text { - Latossolos de textura argilosa } \\
\text { - Terra roxa Estruturada }\end{array}$ \\
\hline $\mathrm{V}$ & 2,0 a 0,0 & - Solos Hidromórficos em relevo plano \\
\hline
\end{tabular}

Fonte: Bertoni e Lombardi Neto (1985).

O Quadro 2 demonstra a relação entre as classes de erodibilidade que aparecem em algarismos arábicos e as classes de declividades, resultando deste cruzamento, as classes de suscetibilidade à erosão laminar, representadas em algarismos romanos. Então, cruzando as informações de erodibilidade com as classes de declividades, é possível chegar ao mapa preliminar de suscetibilidade erosiva.

Quadro 2 - Definição das classes de suscetibilidade à erosão laminar: Relação Erodibilidade X declividade.

\begin{tabular}{|c|c|c|c|c|}
\hline \multirow{2}{*}{ Erodibilidade } & \multicolumn{4}{|c|}{ Declividade } \\
\cline { 2 - 5 } & I (>20) & II (12 a 20) & III (6 a 12) & IV $(<6)$ \\
\hline 1 & I & I & II & II \\
\hline 2 & I & II & III & IV \\
\hline 3 & II & III & IV \\
\hline 4 & III & IV & Não existe & V \\
\hline 5 & Não existe & Não existe &
\end{tabular}

Fonte: IPT (1990) apud Sousa (2006).

Para cada classe de erodibilidade são estabelecidas as respectivas classes de suscetibilidade, conforme tipos de solos e declividades, sendo as seguintes as classes possíveis: I - Extremamente suscetível; II - muito suscetível; III - moderadamente suscetível; IV - pouco suscetível e V - pouco a não suscetível.

O trabalho contou ainda com um tratamento de hipótese dos mapas de suscetibilidade. Considerando os valores de ocorrências dos graus de suscetibilidade erosiva encontrados para cada um dos mapas de suscetibilidade, foi então realizado o teste de proporções, para ver se os resultados dos mapas de suscetibilidade erosiva obtidos são dependentes ou independentes das classes de declividades adotadas. Para tanto se utilizou o método do qui-quadrado ( $\chi 2$ ), extraído de Beiguelman (2002) para verificar se o mapa $\mathrm{A}=\mathrm{B}$ ou A \# B. Como base para os cálculos utilizou-se os graus de suscetibilidade de cada mapa, onde se avaliou o número de ocorrências observadas $(\mathrm{O})$, e estimadas (E).

Os valores de (E) foram calculados considerando os valores das ocorrências obtidas para os mapas A e B a partir do quadro de contingência conforme a equação que se segue: 
$\mathrm{Ex}: \mathrm{Al}=6 \cdot \frac{3}{14}=1,28$

Onde:

De AI: A refere-se à variável A (mapa A);

I - refere-se a classe I:

6 = somatório de ocorrências $(\mathrm{O})$ referentes á variável A;

3 = somatório de ocorrências entre A e B;

14 = somatório total de ocorrências de A e B.

O cálculo acima é realizado para as demais classes de A e B

Com a soma das ocorrências (conforme equação acima), foi criado um quadro de contingência, e a partir do mesmo foi possível calcular o valor (d2/e) que corresponde a cada uma das células, para obter o $\chi 2$ utilizando a seguinte equação:

$$
\lambda^{2}=(O-E)^{2} / E
$$

Posteriormente foi definido o grau de liberdade, onde se fez a contagem do número de colunas (graus de suscetibilidade erosiva) - 1 x número de linhas (mapa A e B) - 1,

$$
E x: G L=(5-1) \times(2-1)=4
$$

Encontrado o grau de liberdade, o mesmo foi cruzado com a tabela do $\chi 2$ para um alfa $(\alpha)$ de 0,05 ou $5 \%$ que forneceu o valor de $\chi 2$ crítico.

\section{RESULTADOS E DISCUSSÕES}

A erodibilidade dos solos adaptada para este estudo ficou definida conforme Quadro 3.

Quadro 3 - Classes de erodibilidade na Bacia do Ribeirão Santo Antônio.

\begin{tabular}{|c|c|c|}
\hline Classes de Erodibilidade & Índices relativos de Erodibilidade & Unidades Pedológicas \\
\hline I & 10,0 a 8,1 & Cambissolos, Neossolos Litólicos \\
\hline II & 8,0 a 6,1 & Argissolos \\
\hline III & 6,0 a 4,1 & Não identificada \\
\hline IV & 4,0 a 2,1 & Latossolos \\
\hline V & 2,1 a 0 & Não Identificada \\
\hline
\end{tabular}

Fonte: Adaptado de Salomão (1996).

Mesmo com intervalos de declividades diferentes, as classes de erodibilidade presentes na bacia foram as mesmas. A expressão não identificada refere-se à ausência de Argissolos de textura argilosa e ao não mapeamento de solos hidromórficos, em função da escala de trabalho.

Com a utilização das declividades propostas por Salomão (1996) a relação erodibilidade x declividade ficou distribuída conforme o Quadro 4.

A expressão não existe refere-se à níveis de suscetibilidade erosiva não identificados na área de estudo. 
Quadro 4 - Classes de suscetibilidade erosiva na bacia do ribeirão Santo Antônio.

\begin{tabular}{|c|c|c|c|c|}
\hline Erodibilidade & \multicolumn{4}{|c|}{ Declividades (\%) } \\
\cline { 2 - 5 } & I (>20) & II (12 a 20) & III (6 a 12) & IV $(<6)$ \\
\hline 1 & I & II & II & Não existe \\
\hline 2 & Não existe & Não existe & III & Não existe \\
\hline 3 & Não existe & Não existe & Não existe & Não existe \\
\hline 4 & Não existe & Não existe & IV & V \\
\hline 5 & Não existe & Não existe & Não existe & Não existe \\
\hline
\end{tabular}

Fonte: Cruzamento declividade/erodibilidade.

A Figura 2 mostra o mapa de declividades elaborado segundo os intervalos de declividades propostos por Salomão (1996). O Quadro 5 mostra as classes de declividade e a área ocupada por cada classe.

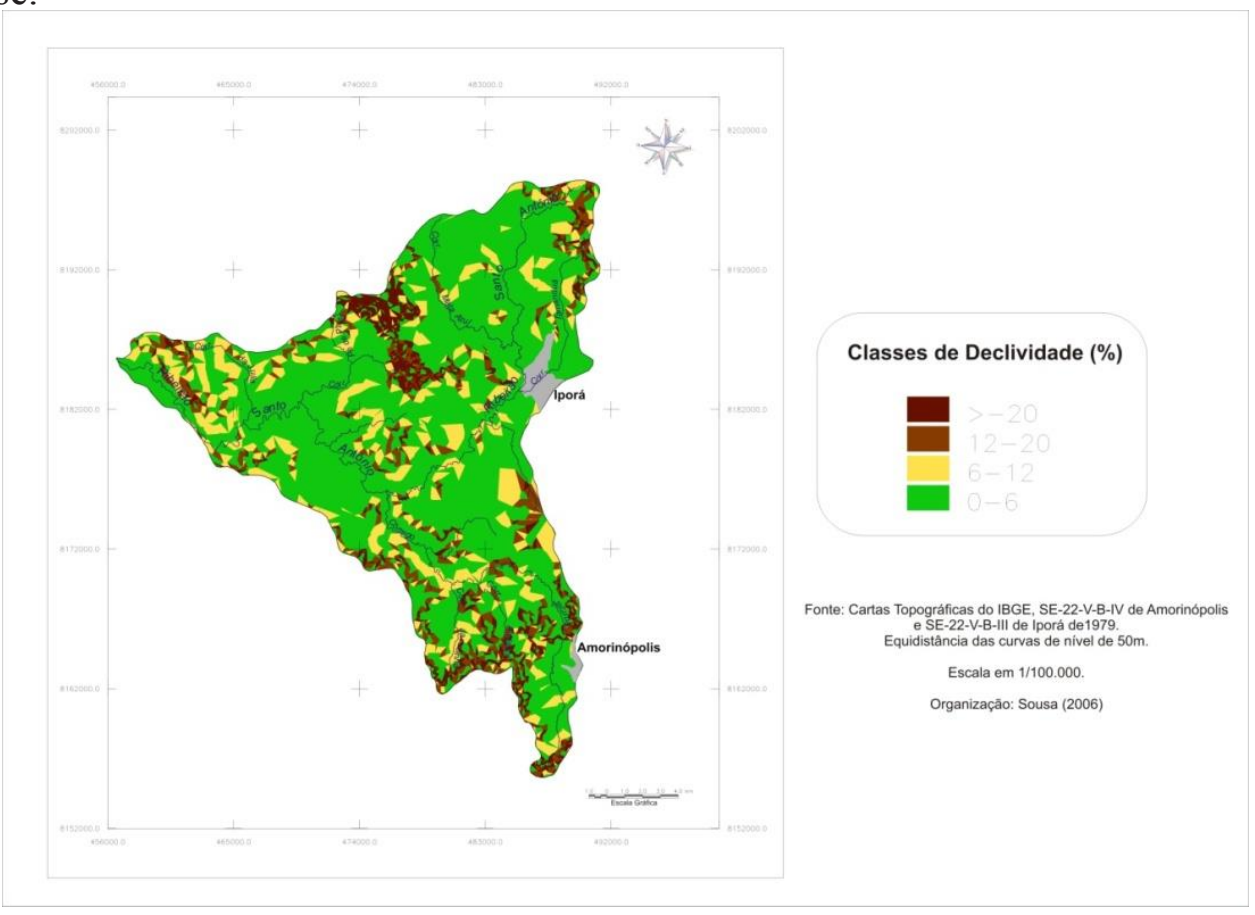

Figura 2 - Mapa de declividade segundo proposta de Salomão (1996).

É possível perceber na Figura 2, que as declividades entre 0 e $6 \%$ predominam na bacia, e a suscetibilidade erosiva predominante neste intervalo de declividade varia de Muito suscetível (classe II) a pouco a não suscetível (classe V). 
Quadro 5 - Classes de declividades e área ocupada na bacia do ribeirão Santo

\begin{tabular}{|c|c|c|}
\hline $\begin{array}{c}\text { Classes de Declividades } \\
(\mathbf{\%})\end{array}$ & $\begin{array}{c}\text { Área ocupada } \\
\left(\mathbf{k m}^{\mathbf{2}}\right)\end{array}$ & Área ocupada (\%) \\
\hline $0-6$ & 468,62 & 68,4 \\
\hline $6-12$ & 89,44 & 16,51 \\
\hline $12-20$ & 50,92 & 10,07 \\
\hline$>-20$ & 55,18 & 5,02 \\
\hline Total & $\mathbf{6 6 4 . 1 6}$ & $\mathbf{1 0 0}$ \\
\hline
\end{tabular}

Fonte: Mapa de Declividade

A bacia como um todo merece uma maior atenção com relação à conservação, pois apresenta $52 \%$ de sua área com suscetibilidades erosivas que variam de muito a extremamente suscetível. A suscetibilidade erosiva na bacia ficou assim distribuída:

Quadro 6 - Suscetibilidade à Erosão Laminar e área ocupada na bacia do ribeirão Santo Antônio.

\begin{tabular}{|c|c|c|}
\hline Classe & Grau de Suscetibilidade & Área (\%) \\
\hline I & Extremamente Suscetível & 10 \\
\hline II & Muito Suscetível & 42 \\
\hline & & \\
& Moderadamente Suscetível & 25 \\
III & & \\
\hline IV & Pouco Suscetível & 3 \\
\hline V & Pouco a Não suscetível & 20 \\
\hline
\end{tabular}

Fonte: Mapa de Suscetibilidade à Erosão Laminar.

Utilizando a proposta de intervalos de declividades de Ramalho Filho e Beek (1995) a relação erodibilidade suscetibilidade ficou definida conforme o quadro abaixo

Quadro 7 - Classes de suscetibilidade erosiva na bacia do ribeirão Santo Antônio
\begin{tabular}{|c|c|c|c|c|c|c|}
\hline \multirow{2}{*}{ Erodibilidade } & \multicolumn{7}{|c|}{ Declividade (\%) } \\
\cline { 2 - 7 } & $0-3$ & $3-8$ & $8-13$ & $13-20$ & $20-45$ & $>45$ \\
\hline 1 & Não existe & Não existe & II & II & I & I \\
\hline 2 & Não existe & IV & III & III & Não existe & Não existe \\
\hline 3 & Não existe & Não existe & Não existe & Não existe & Não existe & Não existe \\
\hline 4 & V & Não existe & Não existe & Não existe & Não existe & Não existe \\
\hline 5 & Não existe & Não existe & Não existe & Não existe & Não existe & Não existe \\
\hline
\end{tabular}

Fonte: Cruzamento declividade/erodibilidade.

A Figura 3 mostra o mapa de declividades com intervalos de declividades propostos por Ramalho Filho \& Beek (1995). Em seguida tem-se o Quadro 4 com as informações sobre classes de declividades e área ocupada por cada classe. 


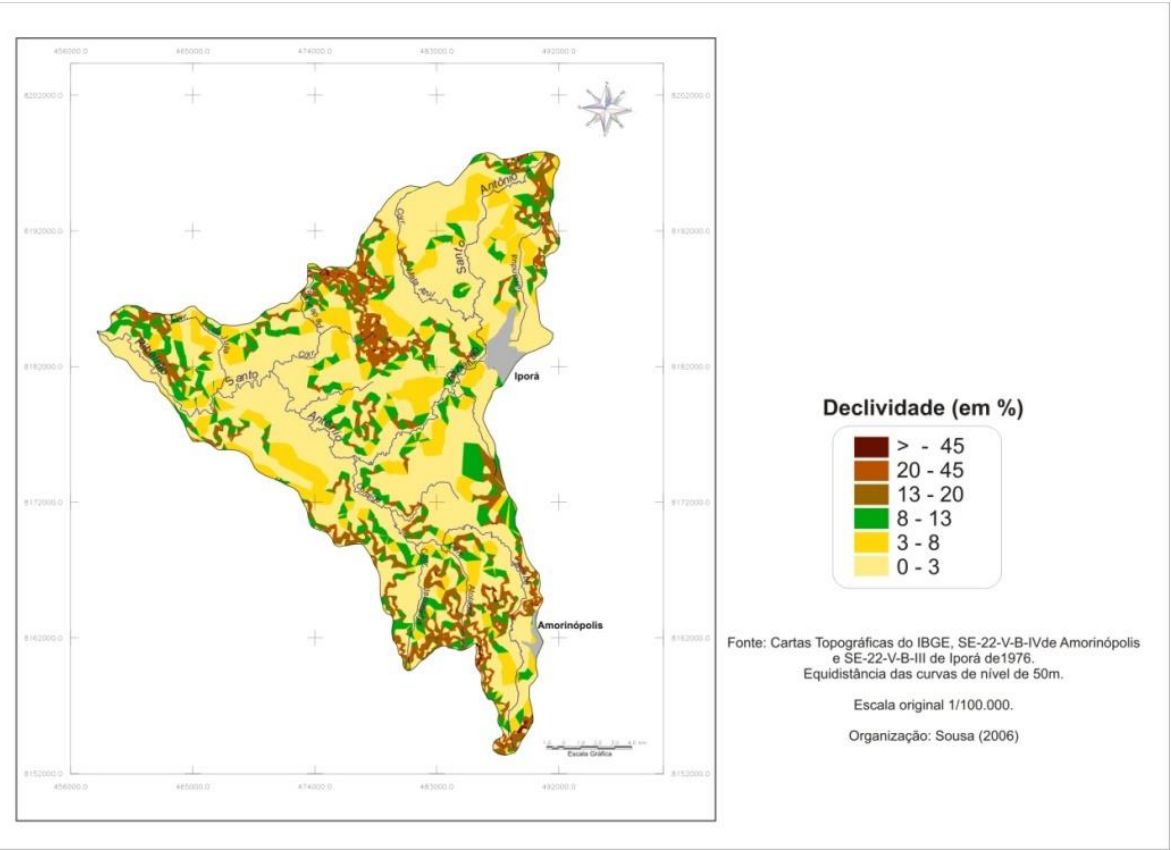

Figura 3 - Mapa de declividades segundo proposta de Ramalho Filho e Beek.

Quadro 8 - Classes de declividades e área ocupada na bacia do ribeirão Santo Antônio.

\begin{tabular}{|c|c|c|}
\hline $\begin{array}{c}\text { Classes de Declividades } \\
(\mathbf{\%})\end{array}$ & $\begin{array}{c}\text { Área ocupada } \\
\left(\mathbf{k m}^{\mathbf{2}}\right)\end{array}$ & Área ocupada (\%) \\
\hline $0-3$ & 374,4 & 56,33 \\
\hline $3-8$ & 109,01 & 16,41 \\
\hline $8-13$ & 80,1 & 12,06 \\
\hline $13-20$ & 45,47 & 6,8 \\
\hline $20-45$ & 34,83 & 5,24 \\
\hline$>45$ & 20,35 & 3,07 \\
\hline Total & $\mathbf{6 6 4 ,} \mathbf{1 6}$ & $\mathbf{1 0 0}$ \\
\hline
\end{tabular}

Fonte: Mapa de declividades

Comparando os dois mapas de declividade e as respostas obtidas para a suscetibilidade erosiva por cada mapa, temos uma distribuição constituída conforme o Quadro a seguir.

Quadro 9 - Graus de suscetibilidade erosiva e número de ocorrências

\begin{tabular}{|c|c|c|}
\hline Grau de suscetibilidade & $\begin{array}{c}\text { №. de ocorrências } \\
\text { Segundo Salomão (1996) }\end{array}$ & $\begin{array}{c}\text { №. de ocorrências } \\
\text { Segundo Ramalho Filho e Beek (1995) }\end{array}$ \\
\hline I & 01 & 02 \\
\hline II & 02 & 02 \\
\hline III & 01 & 02 \\
\hline IV & 01 & 01 \\
\hline V & 01 & 01 \\
\hline Totais & $\mathbf{0 6}$ & $\mathbf{0 8}$ \\
\hline
\end{tabular}

Fonte: dados da pesquisa.

A Figura 3 mostra o mapa de suscetibilidade erosiva resultante do cruzamento com as declividades propostas por Salomão (1996), onde é possível perceber três (3) classes de erodibilidade e seis classes de suscetibilidade. 


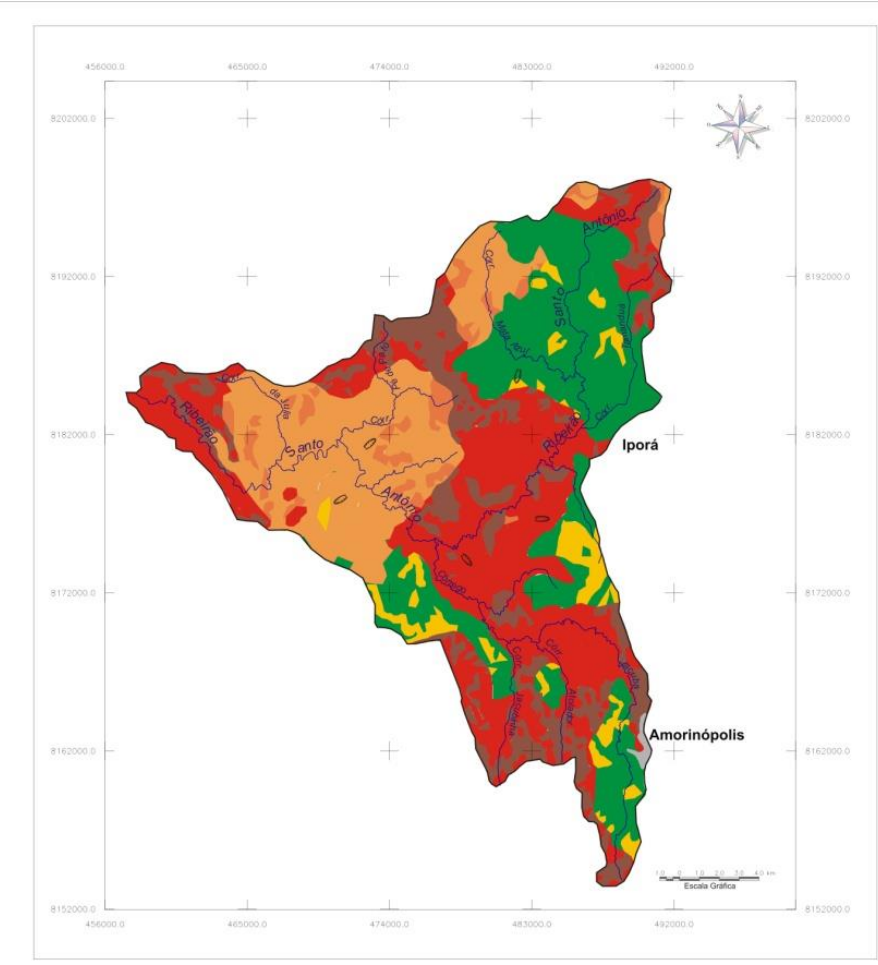

\section{LEGENDA}

SUSCETIBILIDADE À EROSÃO LAMINAR

\section{ERODIBILIDADE CLASSE I}

CLASSE DE SUSCETIBILIDADE II - MUITO SUSCETIVEL

- CLASSE de SUSCETIBILIDADE I- EXTREMAMENTE SUSCetivel

ERODIBILIDADE CLASSE ॥

- CLASSE DE SUSCETIBILIDADE III - MODERADAMENTE SUSCETIVEL

CLASSE DE SUSCETIBILIDADE II - MUITO SUSCETIVEL

ERODIBILIDADE CLASSE IV

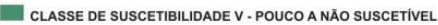

CLASSE de SUSCETIBILIDADE IV - POUCO SUSCETIVEL

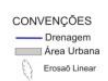

Fonte: Cruzamento do mapa de solos e declividade Adaptado de Salomão, 1995.
Organização: Sousa (2006)

Figura 4 - Mapa de suscetibilidade erosiva com declividades de Salomão (1996).

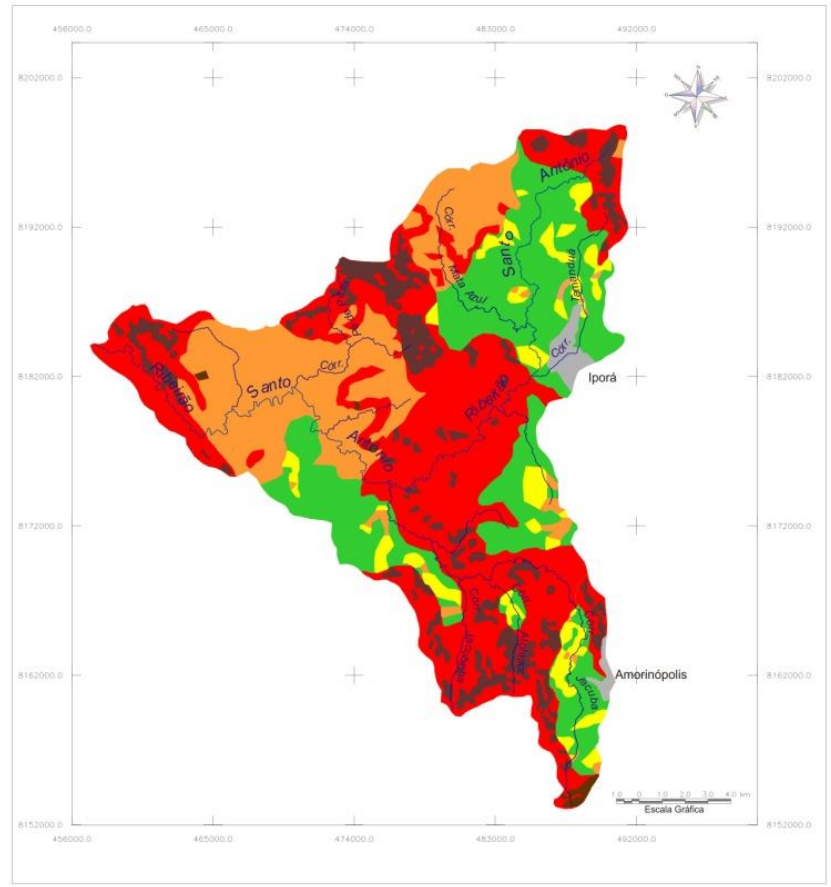

\section{LEGENDA}

SUSCETIBILIDADE À EROSÃO LAMINAR

\section{ERODIBILIDADE CLASSE I}

- CLASSE DE SUSCETIBILIDADE II - MUITO SUSCETIVEL

- CLASSE de SUSCETIBILIDADE I- EXTREMAMENTE SUSCETIVEL

ERODIBILIDADE CLASSE II

CLASSE DE SUSCETIBILIDADE III - MODERADAMENTE SUSCETIVEL

CLASSE DE SUSCETIBILIDADE II - MUITO SUSCETIVEL

CLASSE de SuscetibiLIDADE I- EXTREMAMEnTE Suscetivel

\section{ERODIBILIDADE CLASSE IV}

- CLASSE DE SUSCETIBILIDADE V - POUCO A Nāo SUSCETIVEL

- CLASSE DE SUSCETIBILIDADE IV - Pouco SUSCETIVEL

CLASSE DE SUSCEETIBILIDADE III - MODERADAMENTE SUSCETIVEL

Fonte: Cruzamento do mapa de solos e declividade.
Adaptado de Salomão, 1995. Adaptado de Salomão, 1995.

Figura 5 - Mapa de Suscetibilidade Erosiva com declividades de Ramalho Filho e Beek (1995).

Considerando os mapas de suscetibilidade à erosão laminar resultantes dos dois procedimentos já descritos, pode-se perceber que os mapas de suscetibilidade erosiva não apresentam muita discrepância entre si, preservando de maneira geral as mesmas distribuições espaciais entre as classes, 
apresentando apenas algumas pequenas inserções de classes, que ora são mais extensas num mapa e ora menores no outro.

Com relação à declividade da área, esta é influenciada por um relevo predominantemente suave ondulado a ondulado de topos convexos, predominando declividades médias entre 0 e $8 \%$. Todavia, as declividades mais acentuadas caracterizam-se por segmentos descontínuos, associados à topos de relevo residual nas formas convexas e aguçadas e às vertentes mais inclinadas estão situadas nas bordas de chapadas sobre rochas das Formações Furnas e Ponta Grossa e Aquidauana.

Conforme Quadro abaixo, onde A e B representam os dois mapas de suscetibilidade obtidos, e GRAU significa os graus de suscetibilidade expressos em cada mapa; O é o número de ocorrências de cada grau de suscetibilidade em cada um dos mapas; E é o valor esperado.

Quadro 10 - Graus de suscetibilidade e número de ocorrências obtidas e esperadas para cada mapa.

\begin{tabular}{|c|c|c|c|c|c|c|c|c|c|c|c|}
\hline GRAU & \multicolumn{2}{|c|}{1} & \multicolumn{2}{|c|}{ II } & \multicolumn{2}{|c|}{ III } & \multicolumn{2}{|c|}{ IV } & \multicolumn{2}{|c|}{ v } & TOTAL \\
\hline MAPAS & 0 & $E$ & O & $E$ & 0 & $E$ & O & $E$ & 0 & E & \\
\hline A & 1 & 1,28 & 2 & 1,71 & 1 & 1,28 & 1 & 0,85 & 1 & 0,81 & 6 \\
\hline B & 2 & 1,72 & 2 & 2,28 & 2 & 1,71 & 2 & 1,15 & 2 & 1,40 & 8 \\
\hline TOTAL & & 3 & & 4 & & 3 & & 2 & & 2 & 14 \\
\hline
\end{tabular}

Fonte: Mapas preliminares de suscetibilidade erosiva.

O grau de liberdade calculado conforme o quadro de contingência acima foi quatro (4), que para um $\alpha$ de 0,05 forneceu um $\chi 2$ igual a 9,488. O $\chi 2$ calculado com base nas ocorrências obtidas e esperadas gerou um resultado igual a 0,41457 , portanto inferior a 9,488. Neste caso ficou explicita a não existência de dependência entre os métodos de Ramalho Filho \& Beek (1995) e o de Salomão (1996), demonstrando pelo resultado que os mapas de suscetibilidade são independentes, ou seja, apresentam uma hipótese nula (H0), determinando que seja possível utilizar qualquer um dos intervalos de declividades experimentados sem modificar o resultado do mapa preliminar de suscetibilidade, com 95\% de confiança.

\section{CONSIDERAÇÕES FINAIS}

A Figura 4 difere muito pouco da Figura 5. Apenas as classes III, IV e V onde se utilizou as classes propostas por Salomão (1996), apresentaram uma área de abrangência ligeiramente maior, principalmente a oeste e norte da bacia. As demais classes apresentam mudanças quase imperceptíveis quando olhadas ligeiramente.

Como a metodologia para a avaliação da suscetibilidade erosiva é a mesma, com índices de erodibilidade dos solos sem alteração, a configuração do mapa se manteve com pouca alteração. Considerando o método estatístico os mapas apresentam 95\% de confiança e os métodos utilizados se comportam como variáveis independentes. Acredita-se assim que as diferenças só ocorreriam de maneira significativa caso se alterasse o número da variável solo (número maior ou menor de classes de solos), ou se modificasse os índices de erodibilidade dos mesmos.

\section{AGRADECIMENTOS}

Ao professor Dr. Douglas Henrique Bottura Maccagnan pela leitura e sugestão ao trabalho.

\section{REFERÊNCIA BIBLIOGRÁFICA}

BeIGUElman, Bernardo. Curso Prático de Bioestatística, $5^{\text {a }}$ Ed. Revisada. Ribeirão Preto: Fundação de Pesquisa científica, 2002. 
BERTONI, J. \& LOMBARDI Neto, F. - Conservação do Solo. Piracicaba/SP: Livroceres, 1985. FILHO, A . R.; BEEK, K.J.K. - Sistema de avaliação da aptidão agrícola das terras. EMBRAPA. Centro Nacional de Pesquisa de Solos-CNPS. Rio de janeiro, 1995.

MAMEDE, L. et all. - Levantamento Geomorfológico. Projeto Radambrasil. (Folha SE.22 - Goiânia). Rio de Janeiro, 1983. (Levantamento de Recursos Naturais 31).

NIMER, Edmon. - Clima da região Centro-Oeste. In: Geografia da região Centro-Oeste. Rio de Janeiro: IBGE, 1977.

SAlOMÃO, F. X. de T. - Controle e Prevenção de Processos erosivos. In: Antônio J. T. Guerra; Antônio S. da Silva e Rosângela G. M. Botelho (orgs.) Erosão e Conservação dos Solos: Conceitos, Temas e Aplicações. São Paulo: Difel, 1996.

SOUSA, F. A. de. Uso e manejo dos solos na bacia hidrográfica do ribeirão Santo Antônio no município de Iporá-GO, como subsídio ao planejamento. (Dissertação de Mestrado). Goiânia: IESA/UFG, 2006, 86p.

Trabalho enviado em março de 2013

Trabalho aceito em abril de 2013 